\title{
ESCULTURA CERÂMICA PÚBLICA: A RELAÇÃO PRODUTIVA ENTRE A ARTE, MUNICÍPIOS E A INDUSTRIA
}

Sérgio Vicente

Virgínia Fróis

Recebido em 19/06/2017

Aprovado em 22/09/2017 
A análise de dois exemplos de escultura cerâmica monumental, concluídas em 1993 e 1998, na cidade de Almada, Portugal, respetivamente o Monumento ao Associativismo e à Vida, é demonstrativa dos modos de promoção e produção da cerâmica adaptada às exigências dos projetos de escultura monumental para o espaço público. Obras que foram a génese de um modelo que levou ao estabelecimento, ao longo dos últimos vinte anos, de fortes ligações entre escultores, universidade, autarquias e os polos mais importantes da indústria cereâmica portuguesa, num contexto de contínua e agonizante crise na industria cerâmica. A análise da história destas duas obras é a história de um modelo de promoção de escultura humanista por órgãos municipais socialmente engajados, no qual a cerâmica de grande escala teve o seu protagonismo na cidade na década de 90, numa época de pujante infraestruturação urbana, contrariando a crise social-urbana de décadas anteriores.

Palavras-Chave: Arte Pública. Cerâmica. Indústria.

\section{UMA NOVA ESCULTURA PARA UM TEMPO NOVO}

$\mathrm{F}$ oi já nos anos 80 do século XX, a década da abertura de Portugal à Europa, que se deu em absoluto a estabilização do regime e das instituições democráticas do país depois do atribulado período pós-revolução de 1974. No início década de 1990, o concelho de Almada, na área metropolitana de Lisboa, ainda era um território com uma malha urbana descontinuada e fragmentada, isto devido à natureza do seu nascimento e desenvolvimento ao longo de décadas, com lacunas ao nível da infraestruturação de equipamentos e serviços públicos essenciais nas zonas mais interiores do concelho.

Foi no fim da década que se clarificaram as regras de atuação ao nível do ordenamento do território, fruto da aprovação dos instrumentos legais que deram acesso aos fundos estruturais comunitários e, deste modo, criaramse os meios que possibilitaram consolidar estratégias e fundamentalmente o necessário e complementar financiamento para obras estruturais para a cidade e seus espaços vivenciais. Apostou-se na reabilitação dos núcleos descaracterizados da cidade, no forte controle dos meios privados de urbanização, e efetivou-se o controle absoluto sobre a urbanização clandestina com a progressiva autonomia dos poderes autárquicos no contexto da jovem democracia, que não é exclusiva de Almada, mas sim de uma conjuntura política que a partir dos anos 80 se caracteriza pela delegação de mais poder nas estruturas locais da administração pública, atribuindo-lhes autonomia e possibilidade de não depender da administração central do estado para propor encomendas de arte pública. 
Vicente (2016) aponta a monumentalização da cidade no pós 25 de Abril, quando aborda a evolução da encomenda de arte pública em Almada. Este foi o tempo em que se lançou as bases de uma visão requalificadora do espaço público e da imagem cultural da cidade: criaram-se as estruturas administrativas que conjugaram os interesses de gestão ao nível da arte, urbanismo e política - um caminho no sentido do estreitar a relação entre a qualificação infraestrutural do território e a qualificação sociocultural da cidade - iniciando, deste modo, aquilo que seria a reelaboração do sistema de significação da identidade social urbana através da escultura urbana.

Em Almada aquela década correspondeu à comunhão da visão estruturada e inteligentemente ideologizada da direção do Centro de Arte Contemporânea (CAC) do município, o que em termos administrativos correspondeu à entrega da gestão e encomenda da arte pública à mesma estrutura que gere os equipamentos museológicos municipais vocacionados para difusão das artes plásticas. Isso justificou, em termos estratégicos, depositar no CAC a responsabilidade de desenvolver uma estratégia programática para a monumentalização da cidade já consolidada, que difundiu aquilo que Ana Isabel Ribeiro (Diretora do Centro de Arte Contemporânea do município até 2017) nomeia de valores simbólicos de primeiro nível, ou seja: valores que tornaram materializáveis os grandes ideais, as grandes causas do concelho, os valores universais. E isso só foi possível por se viver em Almada um ambiente político de afirmação muito particular dos valores do Poder Local democrático.

As obras que naquela época aparecem na cidade, mais do que uma colagem ao modelo modernista da escultura 'para-quedas' na cidade, vêm questionar de uma forma acutilante o carácter urbano do Monumento numa cidade que estrategicamente se afirmava na área periférica de Lisboa. Neste ponto, importa referir que o monumento, em Almada, subsiste recuperando a origem etimológica do latim: 'monumentum' que para Françoise Choay tem a sua especificidade urbana na capacidade de mobilizar coletiva e afetivamente a memória com propósitos específicos de preservar e valorizar a expressão identitária de uma qualquer comunidade.

Bohigas (1986, p. 103) acrescenta que o fator que lhe dá sentido de permanência, mais do que ser representante de uma determinada dimensão da identidade coletiva, é a sua capacidade de dar visibilidade a essa mesma identidade, ou seja, um forte carácter urbano, que para Vicente (2016), dáse de fato em Almada, a passagem do paradigma do monumento figurativo para o monumento de formas mais abastractizantes e de feição monumental. As autarquias assumem a encomenda de esculturas de grande escala, o que no contexto político anterior não era possível (salvaguardando Lisboa e Porto). Em Almada aposta na monumentalidade foi fulcral para a manutenção do sentido de cidade no meio das profundas e muitas vezes desiguais vias do desenvolvimento suburbano da capital. 
Desse modo, uma 'nova escultura' surgiu em Almada, assente em novos pressupostos ideológicos tendentes à universalização das temáticas. Deixamos de ter monumentos relacionados com acontecimentos históricos constitutivos de um imaginário nacionalista e patriótico e passamos a ter obras em torno da exacerbação da experiência democrática, no período de afirmação dos valores guiados pela Revolução a partir do 25 de Abril de 74, ao que se acrescentou uma visão estratégica tendente à harmonização entre o planeamento urbano e a arte pública, num confronto permanente com o dia a dia da cidade.

\section{DOIS CONCURSOS: UMA MESMA MATÉRIA}

\} \begin{array} { l } { \text { uma fase de amadurecimento político, no plano de atividades da } } \\ { \text { presidência do município para 1995, afirmava-se que já estava terminado } } \\ { \text { o monumento ao Associativismo Popular, e apontava-se que começara } } \end{array} já a concretização de um outro grupo limitado, mas singular de monumentos: lançou-se um concurso público, que veio a ser para o Monumento à Vida a edificar na praça Lima de Freitas, evocando 'causas maiores da humanidade.'

A ideia de concretizar um monumento ao Associativismo almadense pelo poder local democrático vinha de 1985 , quando foi exarada no plano de atividades para esse ano a vontade de "valorizar o património cultural monumental, iniciando o estudo, conjuntamente com as coletividades, para a edificação em Almada de um monumento ao Associativismo" (Jornal de Almada, 1973).

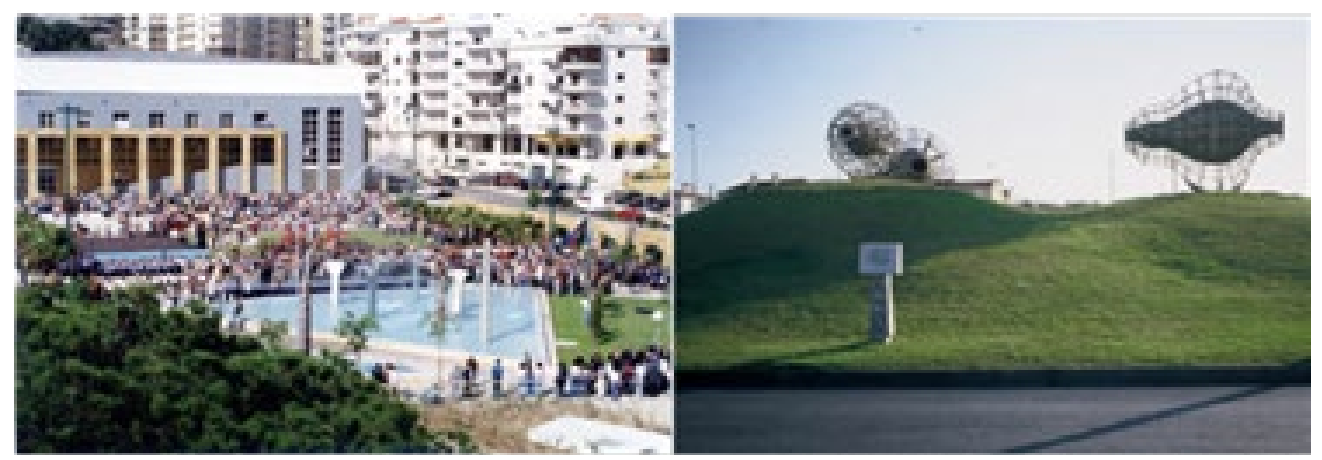

Fig. 1: Os dois exemplos de escultura cerâmica de grande escala presentes em Almada, de 1994 e 1998 respetivamente: a inauguração a 29 de maio de 1994 do Monumento ao Associativismo Popular de Virgínia Fróis e o Monumento à Vida de Sérgio Vicente. 
Teremos, contudo, de recuar dez anos para perceber o sentido e a vontade desta homenagem. De fato, ainda estava latente na memória de todos a ideia lançada num semanário local, no ano de 1973, pela caneta de Romeu Correia, um intelectual influente no concelho - de homenagear o associativismo com um monumento em Almada. Quinze anos depois começaram definitivamente "os contactos com o Movimento Associativo do Concelho com vista à elaboração do Programa, visando o Concurso de Ideias" (CMA, 1988) para o monumento, com o objetivo de a sua inauguração ocorrer em 1988.

No entanto, sua concretização foi sendo sucessivamente adiada, e só encontrou a sua grande razão impulsionadora com a realização, em Almada, de um congresso nacional do movimento associativo, já em 1993. A obra foi pensada para ficar instalada nos espaços exteriores do Complexo Municipal de Desportos Cidade de Almada, que finalizara a sua primeira fase de construção e que seria inaugurado, por ocasião do Congresso, em outubro daquele ano.

Para o efeito, estabeleceu-se o regulamento de um concurso público limitado por convite para a conceção do monumento, e foram assim convidados para apresentar propostas os escultores Virgínia Fróis, Jorge Vieira e Virgílio Domingues. E foi em reunião, em 12 de abril de 1993, que se decidiu o vencedor do concurso. O júri, tendo-se "congratulado com a qualidade dos projetos apresentados", acabou por unanimidade por pronunciar-se a favor da proposta apresentada por Virgínia Fróis, por demonstrar uma “(...) elevada capacidade inovadora de integração do espaço físico de implantação” (CMA, 1993).

$\mathrm{O}$ monumento foi financiado através de protocolo entre a Câmara e o urbanizador da vasta área urbana em torno do complexo desportivo. Este modelo de financiamento, que já custeara um conjunto de obras na mesma altura, ganhou com o sucesso do monumento ao Associativismo Popular a forma de modelo operativo, fundamental para as operações de planeamento da escultura para os anos seguintes.

Embora a inauguração do monumento não tenha coincidido com o Congresso de 93, não deixou de ser ovacionado, em 1994, o fato de o movimento associativo do concelho estar representado num Monumento construído por iniciativa camarária e, no entender da municipalidade, o único monumento ao associativismo no mundo (CMA, 1995). O forte sentido simbólico da obra foi evocado no momento da inauguração pela autora: água o elemento ativo, veículo de ideias geradora de projetos. As formas orientam a água, estabelecem marcos, lugares de origem. Sendo o seu apontamento formal entendido por todos aqueles que tinham dúvidas sobre o seu carácter representativo do movimento associativo: no meio de um lago, uma série de colunas construídas em grés projetam água num jogo de interdependências.

Por seu lado, com o concurso público para o Monumento à Vida, deu-se o arranque de um programa com uma nova visão sobre as 'alegorias universais' a serem projetadas através da escultura monumental para uma cidade que 
lançava as últimas bases da infraestruturação básica do território e apontava um novo caminho na promoção da qualidade do espaço público, associado à regeneração urbana e à cultura ambiente na urbe.

Foi chamada à sessão de Câmara de dezembro de 1994 a proposta de regulamento para o concurso público do Monumento à Vida, que só seria realmente divulgado publicamente pelo Município em 1996. Sintetizava-se: “(...)um monumento à vida, que seja um sinal, que seja uma marca de esperança, um sonho perpetuável, para todos os que se empenham ou empenharam nos múltiplos aspectos que concorrem e se implicam na construção da cidade”.

O monumento à Vida foi pensado pela autarquia para se localizar numa das entradas da cidade. Dada a natureza do local, esta rotunda funcionaria como uma das 'portas da cidade', por isso, propunha-se a idealização de um elemento sinalizador sobre o território. Na proposta de regulamento, a levar a sessão de Câmara, faz-se também um paralelismo metafórico entre o construir do monumento e a construção coletiva da cidade: "(...) cidade que pulsa, que se desenvolve na procura de harmonia do seu ambiente, da criatividade da sua força cultural, do bem-estar social para os homens, mulheres e crianças que a habitam".

Aponta-se ainda a necessidade de o projeto ser desenvolvido numa perspetiva multidisciplinar, questão que pressupunha o acerto com uma visão ampliada do desenho da cidade, considerando que o empreendimento impunha diferentes disciplinas na conceção da obra, com o fito de resolver uma grande área de território, de grande complexidade e enquadramento urbano, já que coincidentemente, estava em desenvolvimento para o local, um projeto de loteamento na forma de uma praça, que se pensava que iria resolver a integração daquela área no contínuo de cidade. A construção do monumento em articulação com a edificação urbana era um fator de qualificação daquele espaço.

Por decisão unânime, em 15 de julho de 1996, o júri do concurso considerou vencedor o concorrente Sérgio Vicente. A ata descreve de forma sucinta o processo de avaliação que culminou com a decisão final sobre a proposta do escultor, “(...) precisamente por considerar que o projeto reunia condições pouco vulgares em obras de arte pública no nosso País, e era, portanto, merecedor de ser edificado". No entanto, o fato de a recomendação do júri ter sido elogiosa em relação à proposta não impediu a posterior expressão de crítica, nos círculos políticos do executivo, ao serem confrontados com a maqueta da escultura.

As consequências são visíveis ao nível do resultado final da obra. A concretização do monumento ficou reduzido à sua estrutura elementar, tendo caído ao nível da encomenda e sob a justificação de um acréscimo significativo de custos, a realização de outras intervenções previstas no projeto levado a concurso que pressupunham uma complementaridade plástica no arranjo da 
envolvente. Por outro lado, a marcação do ato de inauguração foi sucessivamente adiada no ano de 1997 até ao limite do ciclo eleitoral; apontou-se depois o ano 1998 para a cerimônia, mas nada de tudo isto foi cumprido. Já em 1998, está anotado no Boletim Municipal que a inauguração seria realizada no dia 21 de maio desse ano, primeiro dia da primavera: uma evocação poética da 'Vida', ato, no entanto, nunca cumprido.

\section{A ESCULTURA EM AMBIENTE DE PRODUÇÃO FABRIL E OS NOVOS PARADIGMAS DA INVESTIGAÇÃO UNIVERSITÁRIA}

$\mathrm{O}$ s monumentos ao Associativismo e à Vida, frutos de concurso público, tiveram a sua materialização em grés, uma matéria plástica que até aquele momento nunca tinha tido protagonismo tão grande ao nível da escultura urbana. Poderemos encontrar as razões desta repentina valorização da escultura cerâmica, fruto da conjugação de um modelo aberto de encomenda da escultura pelo município, para o qual convidara como membros do júri uma geração de artistas que anos antes já contactaram com os modos de produção cerâmica, a que estava associada uma visão alargada do sentido erudito das artes plásticas. Assim, em meados dos anos 90 do século passado, quando se apresentaram a concurso projetos que elegem o uso da matéria cerâmica com matéria primeira da escultura urbana, encantaram o júri com as possibilidades monumentais inscritas nas propostas. Aquelas propostas seriam a síntese programática da 'união de todas as artes', uma expressão cultural e plural de uma cidade em profundo desenvolvimento.

Também foi um tempo em que artistas que conviveram com Jorge Vieira - o escultor responsável pela afirmação, no modernismo português, da escultura cerâmica como uma das matérias nobres da arte (no contexto universitário das Belas Artes Virgínia Fróis foi professora assistente de Jorge Vieira e Sérgio Vicente foi aluno de Jorge Vieira e de Virgínia Fróis) - se deixaram influenciar não somente pelo gosto da modelação e da matéria definitiva da escultórica em cerâmica, mas igualmente pelas reais possibilidades que o grés oferecia à obra púbica. E percebia-se que essa possibilidade era real, havendo a disponibilidade das fábricas para trabalhar com os escultores em projetos com exigências absolutamente novas para o trabalho artístico e industrial.

Estes laços reforçam-se, porque a materialização da escultura cerâmica já existira e estava marcada por encomendas estatais pré-revolução (Elias, 2006) e pós-revolução no País (Elias \& Leonor 2012). Vejam-se encomendas de murais cerâmicos e escultura cerâmica em Lisboa (Jorge Barradas, Júlio Pomar, Jorge Vieira, Abel Manta, Manuela Madureira, etc.) ou Almada com Cargaleiro. A novidade da encomenda cerâmica para Almada no contexto do poder local 
é o fato de esta deixar de estar suportada por uma estrutura arquitectônica. $\mathrm{O}$ paradigma é o da escultura cerâmica de vulto perfeito no espaço público, ao invés de adossada, em baixo ou alto relevo.

Estas novas possibilidades de trabalhar a grande escala entrou em conflito com o modelo tradicional da experiência criativa na cerâmica. Genericamente, esta estava adstrita à capacidade dos escultores ceramistas auto-produzirem as relações estéticas da obra, ou seja, reproduzirem o uso de um código próprio pensado como linguagem, que se materializava em soluções plásticas ao nível dos objetos de cerâmica.

O projeto escultórico tornou-se assim mais exigente a nível de complexidade na produção e estrutura de implantação. Desta forma, o exercício da escultura relaciona-se mais com o desenho urbano do que com a arquitetura, nomeadamente a sua aplicação no revestimento de superfícies arquitetônicas. A monumentalização da escultura cerâmica em Almada, através da obra destes autores, marca a mudança de paradigma na escultura pública do concelho.

Nas obras que se vieram a produzir para Almada, a linguagem dos artistas esteve definitivamente dependente da análise das características específicas dos materiais a serem usados na configuração da obra, para o lugar específico da sua implantação. Este fato provocou modificações substanciais na forma e no modo de relacionamento estético entre os escultores e a sua experiência plástica trazida até aquele momento. A complexidade dos projetos obrigou, no âmbito da produção fabril, à intervenção de diferentes agentes na manufaturação e na construção da mesma. Deste modo, a execução das obras dependeu do averbamento de uma série de modelos processuais autonomizados nos meios de produção, e ao qual ao artista esteve vedado o controle processual, já que este foi distribuído por um determinado número de pessoas especializadas em determinadas etapas da realização, que incluem técnicas complexas e conhecimentos específicos associadas à cerâmica, embora os artistas acompanhassem e supervisionassem, como é lógico, todo o procedimento tecnológico.

Depois a obra regressou à 'posse' dos escultores para ser acabada ou novamente intervencionada. Note-se e reafirme-se que os artistas foram o garante dos critérios de originalidade, no entanto, os processos criativos deixaram naquele contexto de ser auto-gerados, isto é, desenvolvidos pelo artista com base no domínio telúrico da linguagem dos materiais cerâmicos, num processo individual continuado, que sempre levaram à especialização cerâmica, em que as obras sempre estiveram associadas à história do artista e aos modos da sua criação. 


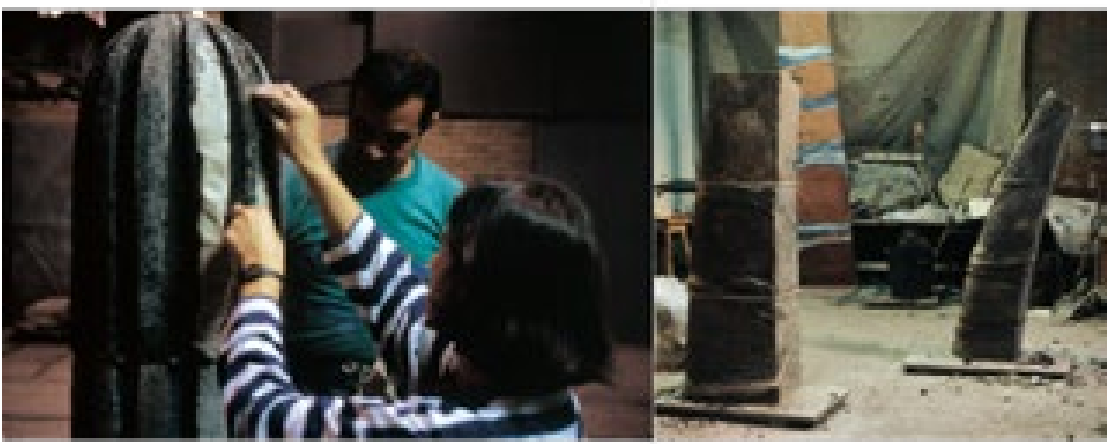

Fig. 2: No verão de 1994, Virgínia Fróis trabalha permanentemente nas instalações da fábrica da Abrigada, onde produziu as suas peças.

Vejamos, Virgínia Fróis, no Verão de 1994, encontrou-se a trabalhar de forma sistemática nos estaleiros da fábrica da Abrigada. Os modos de produção disponíveis passaram por uma equipe de moldadores manuais, formados em sucessivas gerações de trabalhadores que desde meados do século XIX foram adaptando os modos de moldagem manual de peças à evolução dos produtos produzidos em grés.

Se a partir da segunda metade do Século XIX, a Abrigada introduziu a fabricação de grés sanitário em Portugal, fruto da boa qualidade das argilas desta zona, diga-se, na fronteira norte da área metropolitana de Lisboa, foi já no século XX que o fabrico de peças para a indústria química e cimenteira concentraram a produção da fábrica. E é aqui que reside a grande mais valia da fábrica da Abrigada: no claro domínio dos modos de produção mecanizado, interdependentes do saber artesanal. Para a escultura, a fabricação de moldes em madeira que se adaptam às particularidades de diferentes peças em grés, e os processos de moldagem manual oferecem ao saber artístico a escala, a seriação e a matéria adequada à escultura de grande formato.

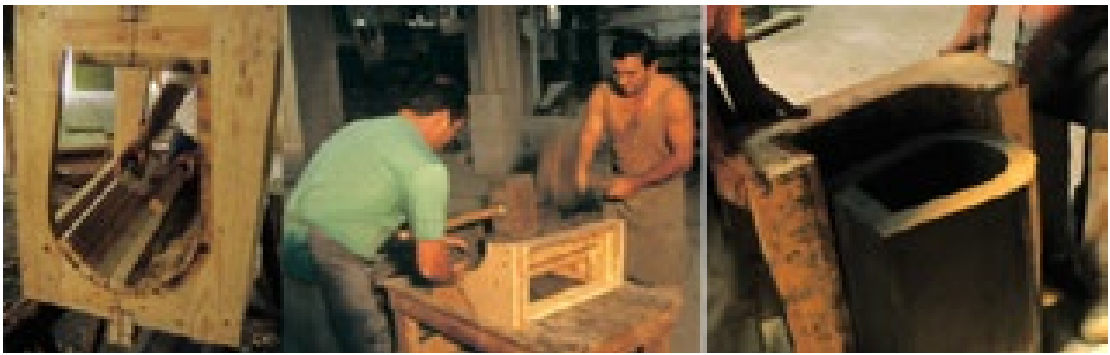

Fig. 3: Os meios de produção disponíveis consistiram numa equipe de moldadores manuais, treinados por sucessivas gerações de trabalhadores que, a partir de meados do século XIX, adaptaram a moldagem manual de peças para a produção em série de produtos em grês. 
Foi com esta experiência dos operários da fábrica que a escultora contou, à qual acrescentou a sua prática na cerâmica, o conhecimento das pastas e das possibilidades de diferentes revestimentos, usando pastas policromadas e zonas vidradas, constituindo-se estes trabalhos como inovações para esta industria.

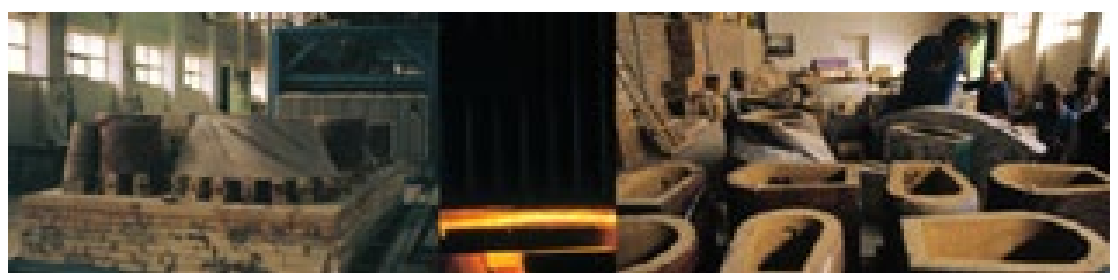

Fig. 4: O método de trabalho baseou-se num diálogo permanente entre os diferentes agentes técnicos, que permitiu a celeridade na escolha da monocozedura a 1.200 graus, sem necessidade de repetição de fornada.

No atelier a escultora desenvolveu o trabalho prévio de ensaio dos materiais para, posteriormente, no laboratório da fábrica, com os técnicos, otimizar os procedimentos, ampliar a escala e colmatar os problemas relativos à sua produção, compatibilizando as matérias e os processos para atingir os resultados estéticos pretendidos. Este modo operatório, baseado num diálogo permanente com os diferentes níveis de decisão da fábrica, permitiu a opção pela mono-cozedura à temperatura de 1200 graus, de modo que pudessem ser bemsucedidas sem repetição no tempo previsto.

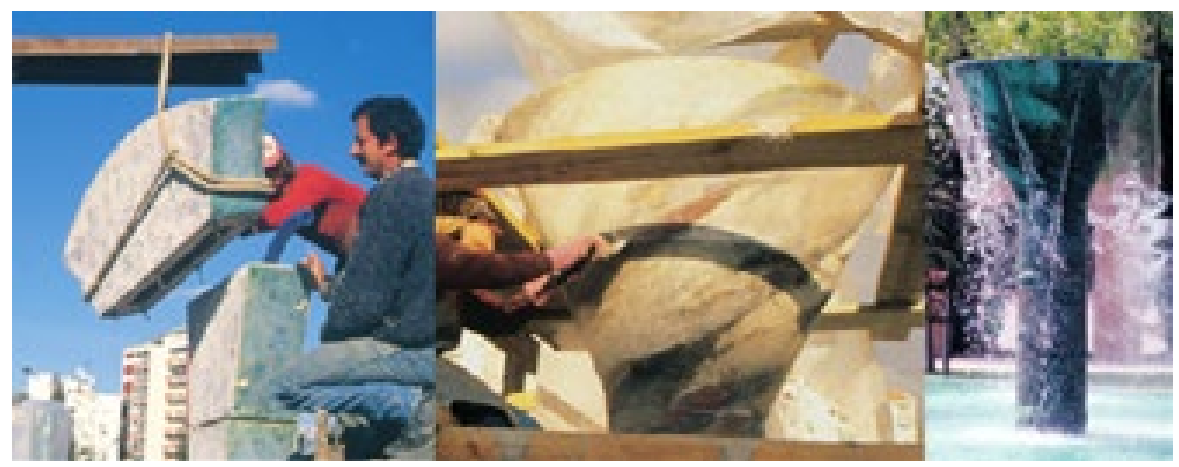

Fig. 5: A construção modular da escultura possibilitou o domínio absoluto sobre os processos de montagem e os acabamentos. 
Por outro lado, o Monumento à Vida foi pensado como uma obra de cariz industrial, ou seja, a construção da escultura esteve intimamente ligada aos modos de produção ancestrais da Abrigada; Sérgio Vicente, durante o projeto de execução do monumento, em 1996 - e de acordo com as premissas deixadas pela escultora Virgínia Fróis, que terminara o projeto na fábrica algum tempo antes -, foi encontrar no ambiente da fábrica os modos de fazer adequados para montar um complexo projeto monumental.

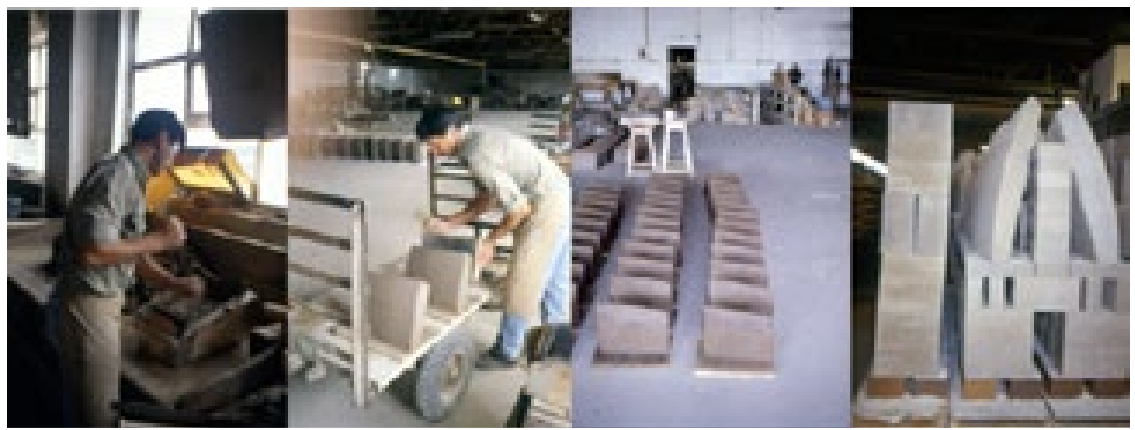

Fig. 6: O monumento à vida foi concebido como uma obra de caráter industrial. Por outras palavras, a construção da escultura esteve intimamente ligada aos modos de produção ancestral da Abrigada: moldagem manual, cofragem de madeira, e a seriação de peças de grés.

Cingiu-se à moldagem manual a partir de cofragem de madeira, de um assinalável conjunto de peças em grés. Depois de desenhadas e entregues os esquiços em fábrica, estas peças modulares entraram na cadeia de produção, só voltando a passar a obra para a posse do artista no momento em que já sobre o terreno se erguia a estrutura metálica exterior do monumento em Almada. Falamos de um corpo, que além de determinar a volumetria da forma escultórica, foi pensado como estrutura primária de suporte dos módulos de grés, que depois de montados no seu interior permitiram a simbiose estética entre matérias e a afirmação de uma geometria elementar própria dos elementos naturais (Vicente, 1998).

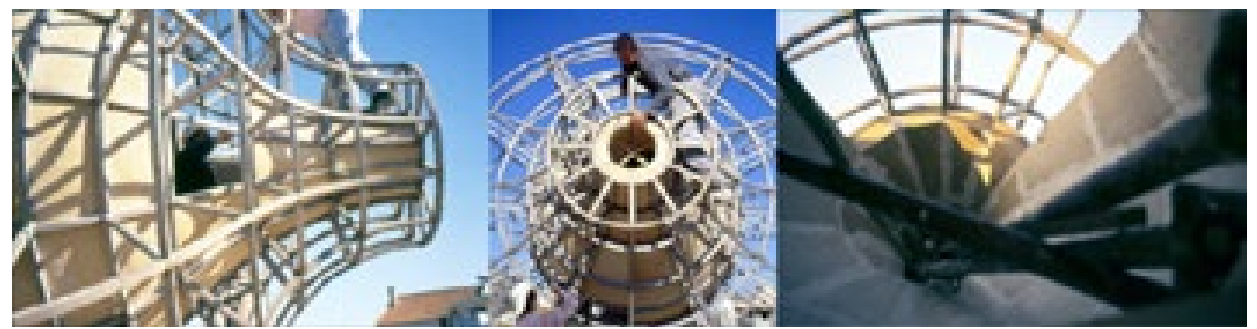

Fig. 7: O corpo de ferro, além de determinar o volume da forma escultural, foi concebido como uma estrutura de suporte primário para os módulos de grés, que, uma vez montados dentro dele, permitiram uma simbiose estética entre materiais e a afirmação de uma geometria elementar própria dos elementos naturais. 
O trabalho desenvolvido por Sérgio Vicente reproduz o que poderemos considerar como o regime alográfico (Remesar, 1997, p. 206) da linguagem escultórica aplicado à arte pública. Enquanto a escultora implementou um modelo de trabalho - no qual considerou a sua intervenção como indispensável à sequenciação da produção, acompanhando e intervindo na procura de soluções técnicas e plásticas em todas as fases do processo -, o escultor depositou nas mãos dos técnicos as soluções tecnológicas que melhor se adaptavam à proposta, deixando o tempo de fabricação como o grande modelador da forma da escultura, uma realidade na qual o escultor se absteve de tomar qualquer decisão, mas claro, acompanhou de forma comprometida todas as fases de produção.

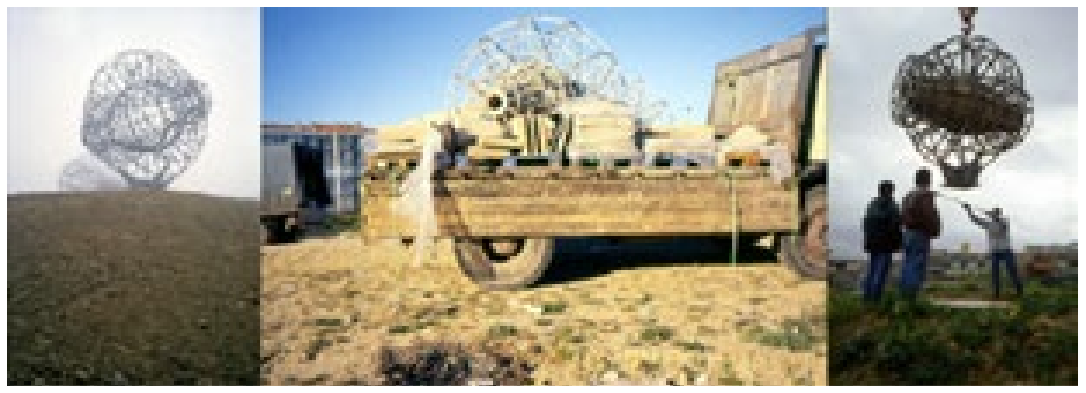

Fig. 8: O trabalho só voltou à posse do artista no momento em que a estrutura metálica do monumento estava a ser erguida no solo em Almada.

\section{CONSIDERAÇÕES FINAIS: OS PROJETOS E A SUA CONTINUIDADE}

$\mathrm{E}$ stes dois monumentos foram a gênese de outras experiências artísticopedagógicas ao longo das últimas décadas. O complexo da fábrica da Abrigada tem possibilitado aos escultores encontrar o ambiente e as condições técnicas adequadas para desenvolver projetos de escultura que sem estas condições de excelência nunca seriam produzidos. Portanto, reuniramse as condições para uma parceria com a Universidade de Lisboa e apostouse na investigação, seja esta ligada ao campo da experimentação plástica, no desenvolvimento tecnológico, na investigação de novas matérias e as suas repercussões no campo artístico e do mercado. 


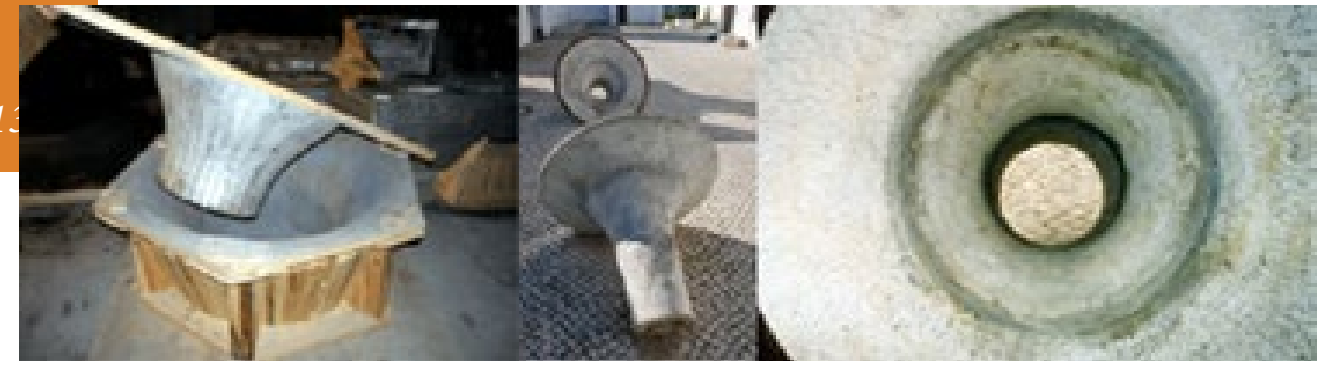

Fig. 9: O trabalho "Comunicação", da escultora Sara Inácio, foi o primeiro resultado visível dessa parceria. Foi o resultado de uma troca entre a Faculdade de Belas Artes, o município de Montijo e a fábrica de Abrigada. Uma escultura colocada no espaço público em 2003, no Montijo, uma cidade ribeirinha da região metropolitana de Lisboa.

A obra 'Comunicação', da escultora Sara Inácio, foi o primeiro resultado visível desta parceria. Foi fruto de um programa de intercâmbio entre a Faculdade de Belas Artes, o município Montijo e a Fábrica da Abrigada; uma escultura colocada no espaço público em 2003, no Montijo, uma cidade ribeirinha na área metropolitana de Lisboa. Tratou-se de uma escultura de grande escala, produzida pelo vazamento de cimento refratário em moldes de madeira.

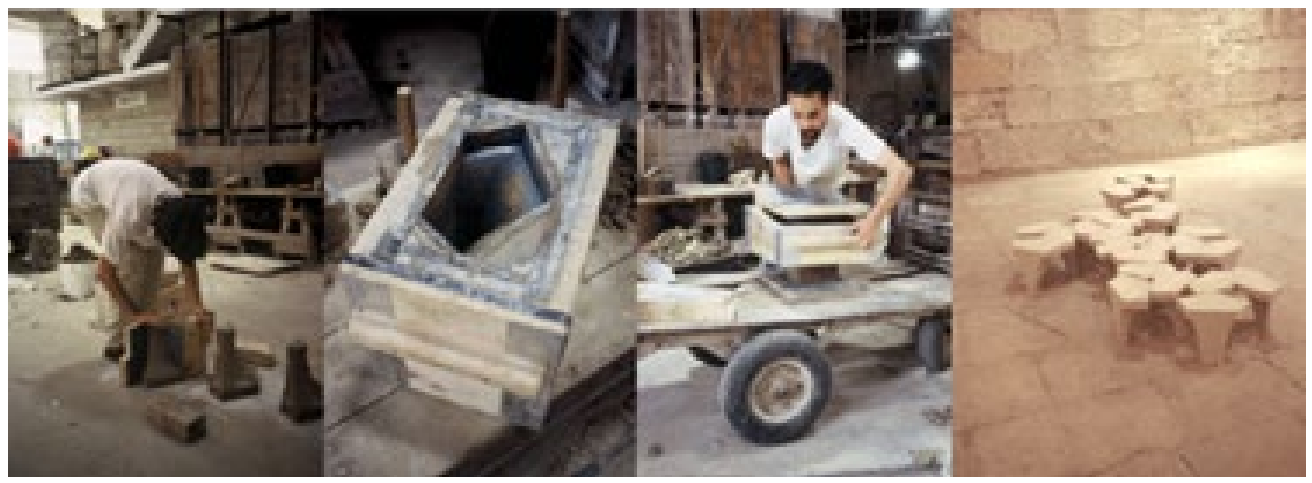

Fig. 10: Num modelo de oficina fabril destacamos o "Modulos Operandi", realizado nas instalações da fábrica de Abrigada. Um grupo de estudantes de Belas Artes reuniu-se em 2003 com o objetivo de realizar projetos de escultura cerâmica a partir de uma perspectiva modular no âmbito da produção industrial. 
Num modelo de workshop, fruto de intercâmbio entre instituições, destacamos 'Modulos Operandi', realizado nas instalações da fábrica da Abrigada. Ali reuniu-se um grupo de alunos finalistas de Belas Artes em 2003, com o intuito de realizar enquadrados no ambiente de produção fabril os seus projetos de escultura cerâmica numa perpectiva modular. Modulus Operandi foi um espaço de experimentação plástica, e os contributos dos professores Sérgio Vicente e Virgínia Fróis e do saber técnico dos funcionários fabris ajudaram na concretização dos projetos dos alunos.

As propostas apresentadas a execução corresponderam a premissas técnicas de adequação à produção industrial, mas refletiram primeiramente as preocupações poéticas dos alunos envolvidos. Se o programa preliminar impunha a realização de um conjunto limitado de módulos, cada peça limitada a um cubo de trezentos milímetros de aresta, as propostas revelaram possibilidades de conjugação entre módulos que ultrapassaram questões de simples jogo formal e questionaram de forma audaz as relações de instalação dos objetos num espaço físico e ambiental, seja pela escala de alguns dos projetos ou a intenção expressamente funcional de outros. A escultura Coluna Modular de Leonor Pego, colocada igualmente no Montijo, foi a parte visível do Workshop.

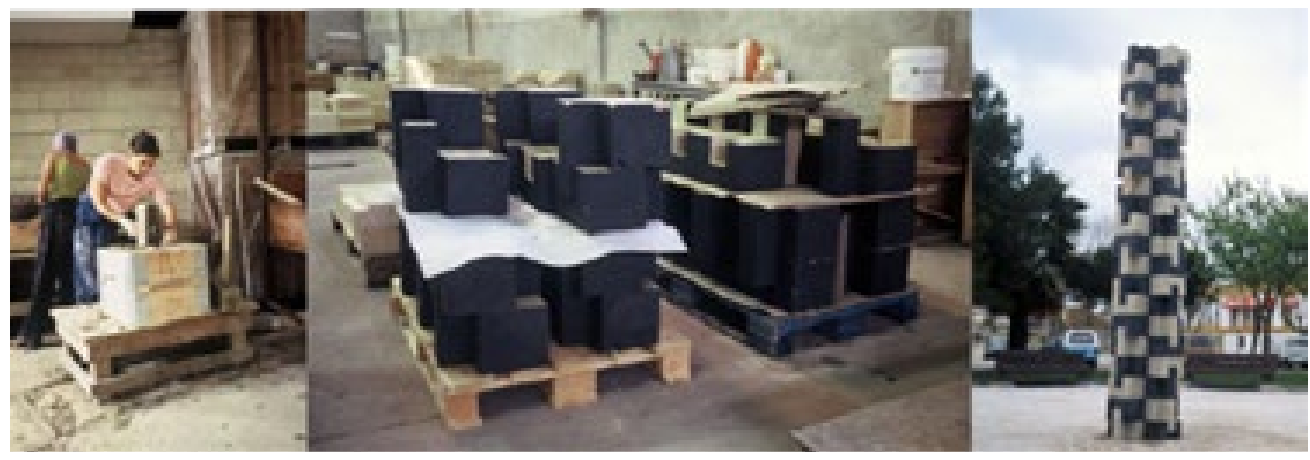

Fig. 11: A escultura 'Coluna Modular' de Leonor Pêgo, também colocada no Montijo, foi a parte pública e visível do Workshop 'Modulos Operandi'. 
Outras parcerias com o Município das Caldas em Rainha e com as fábricas SECLA, já extinta, e a revitalizada Fábrica Bordallo Pinheiro, fundada por este artista em 1884, fora um importante centro cerâmico com numerosa indústria, destacando-se a faiança, os objetos utilitários, o revestimento azulejar e a própria escultura de Raphael Bordallo Pinheiro. Estes foram os locais onde se realizou o projeto Mercado da Fruta, em 2003.

De referir a atividade organizada pela Associação de Arte e Comunicação Oficinas do Convento (1996) em parceria com o Município de Montemor-o-Novo, promoveram a recuperação de uma manufatura de tijolo e da arquitetura de terra, hoje um local de produção artística, destacando-se as residências no âmbito da Cerâmica. Salientamos o simpósio internacional Habitar 2001, como a participação ativa de alunos FBAUL como assistentes dos escultores, colaborando na produção das seis esculturas instaladas na cidade.

Estes foram, com toda certeza, os espaços de trabalho mais adequados e empolgantes para a aquisição de conhecimentos técnicos e artísticos. Estes são exemplos do investimento institucional em parcerias a longo prazo com a indústria e o poder local, que não deixaram de ter as suas raízes na experiência que os dois escultores trouxeram dos concursos públicos em Almada na década de 90 do século passado. Investimento que hoje, definitivamente, contribui para encontrar soluções técnicas e artísticas inovadoras e ajudar a atenuar crescentes dificuldades econômicas na indústria cerâmica e, diga-se, colmatar insuficiências ao nível técnico-científico no ensino artístico universitário. 


\section{REFEREANCIAS}

BOHIGAS, O. Reconstrucción de Barcelona. Barcelona: Servicio de

Publicaciones, Secretaría General Técnica, Ministerio de Obras Públicas y Urbanismo, 1986.

CÂMARA MUNICIPAL DE ALMADA. Relatório Atividades Conta de Gerência: 1987. Almada: CMA, 1988.

CÂMARA MUNICIPAL DE ALMADA. Concurso público limitado por convites para a conceção de um Monumento ao Associativismo Popular. Abr. 12. (Ata de reunião de Júri). Almada: CMA, 1993.

CÂMARA MUNICIPAL DE ALMADA. Destaque. In: Boletim Municipal. (6), 2. Almada: CMA, 1995.

CÂMARA MUNICIPAL DE ALMADA. Almada vai ter um Monumento à Vida. In: Boletim Municipal, (27), 17. Almada: CMA, 1998.

CHOAY, F. A alegoria do património. Lisboa: Edições 70, 2006.

ELIAS, H. Arte Publica das administrações central e local do estado novo em Lisboa (1938-1960) Barcelona: Universidade de Barcelona, tese de Doutoramento, acedido em: http://diposit.ub.edu/dspace/handle/2445/35438.

Elias, H. \& Lonor, S. Intervenções artísticas nos espaços públicos nos anos setenta em Portugal: uma análise a partir das publicações sobre arte surgidas ao longo da década, actas da SOPCOM, Lisboa, 2012, pp. 1-12, acedido em: www. academia.edu/15993389/Intervenções_artísticas_nos_espaços_públicos_nos_ anos_setenta_em_Portugal_uma_análise_a_partir_das_publicações_sobre_ arte_surgidas_ao_longo_da_década. 
JORNAL DE ALMADA. Uma Carta de Romeu Correia. Almada. Set. 15. 1973.

138 REMESAR, A. () Hacia una Teoría del Arte Público, in: “@rtepúblico”, Barcelona: Universidad de Barcelona, 1997.

VICENTE, S. Três esculturas, vinte desenhos e estudos, maquetes e projecto do monumento à vida. Almada: Casa da Cerca/ Câmara Municipal de Almada, 2000.

VICENTE, S. A escultura como expressão pública da cidadania A monumentalização da cidade de Almada entre 1974 e 2013, Lisboa: Universidade de Lisboa: Tese de Doutoramento, 2016, acedido em: www. repositorio.ul.pt/bitstream/10451/24023/1/ulsd072889_td_Sergio_Silva.pdf. 